REVISTA DE DERECHO UNED, NÚM. 17, 2015

\title{
LA VIOLENCIA SEXUAL COMO UN ATENTADO CONTRA LA DIGNIDAD DE LA MUJER
}

\author{
SEXUAL VIOLENCE AS AN OUTRAGE AGAINST WOMAN'S \\ DIGNITY
}

\section{MAXIMILIANA GIL}

\section{Doctora en Derecho URG (Venezuela)}

Resumen: La violencia sexual contra la mujer es la manifestación extrema de la desigualdad y del sometimiento en el que viven las mujeres en el mundo. Constituye un atentado contra el derecho a la vida, a la libertad, y la dignidad de las mujeres. Por tanto, para comprender la magnitud del daño que causa la violencia sexual debe ser vista como un atentado de y para la dignidad humana de la mujer. Así que, el objeto de la presente investigación es estudiar la violencia sexual como un atentado contra la dignidad de la mujer, a través de un análisis documental con un diseño crítico-analítico y la técnica utilizada fue la interpretación jurídica.

Palabras claves: Violencia sexual, Dignidad humana, delitos prescriptible, imprescriptibilidad.

Abstract: The sexual violence against women is the extreme manifestation of equality and submission that women live, in the world. It is an outrage against right to life, safety, from and to human woman's dignity, therefore, to understand the magnitude of this damage which is inflected by this violence, it must be seen as an outrage from an to human woman's dignity. Because of that, the focus of this research is to study the sexual violence as an outrage against woman's dignity. This thesis is a documentary using a critical-analytical design, and a legal interpretation.

Keywords: sexual violence, human dignity, precriptible felonies, imprescriptib.

Recepción original: 27/08/2015

Aceptación original: 30/09/2015

(C) UNED. Revista de Derecho UNED, núm. 17, 2015 
Sumario: I. Introducción. II. Dignidad humana. III. Violencia sexual. IV. Fundamentos legales. V. Opiniones especializadas. La violencia sexual como un atentado contra la dignidad de la mujer. Perspectiva jurídica, psicológica, teológica y filosófica. VI. Propuesta para una reforma de la ley orgánica sobre el derecho de las mujeres a una vida libre de violencia, perspectiva: la violencia sexual como un delito imprescriptible. VII. Conclusiones.

\section{INTRODUCCIÓN}

La violencia sexual es una problemática mundial que en las últimas décadas ha sido reconocida como una violación de los derechos humanos, sexuales y reproductivos que vulnera la dignidad humana, la integridad, la libertad, la igualdad y autonomía. Se constituye en un flagelo a la salud pública por su magnitud y las afectaciones que produce en la salud física, mental y social ${ }^{1}$.

Por tanto, esta investigación plantea que para comprender la magnitud del daño que causa la violencia sexual debe ser vista como un atentado de y para la dignidad humana de la mujer.

Así que, el propósito de este trabajo es estudiar la violencia sexual como un atentado contra la dignidad de la mujer. A través de este estudio se realizó una revisión detallada de la magnitud de daño causado por la violencia sexual en la valoración de la mujer como ser humano: desde el enfoque jurídico, psicológico y teológico, se analizó a la luz de la legislación internacional y nacional la violencia sexual como un delito imprescriptible y por último se elaboró una propuesta para la reforma de la ley orgánica sobre el derecho de las mujeres a una vida libre de violencia, perspectiva: la violencia sexual como un delito imprescriptible.

El estudio del problema se acerca al análisis y desarrollo de un tema socio-jurídico importante de actualidad, respecto a la «violencia sexual como un atentado contra la dignidad de la mujer en Venezuela», que transgrede derechos fundamentales consagrados en la Constitución de la República Bolivariana de Venezuela.

${ }^{1}$ Exposición de motivos de la Ley Orgánica sobre el Derecho de las Mujeres a una Vida Libre de Violencia (2007): «...La violencia en contra de la mujer constituye un grave problema de salud pública y de violación sistemática de sus derechos humanos, que muestra en forma dramática, los efectos de la discriminación y subordinación de la mujer por razones de género en la sociedad...» 
Lo que deja en evidencia, en primer lugar que es necesario, ampliar el espectro del análisis, en razón que el impacto de la violencia ejercida contra la mujer, va más allá de la cuantificación de los daños físicos o psicológicos, es preciso reflexionar y visibilizar a plenitud la verdadera afectación causada a la mujer abusada sexualmente. En segundo lugar, representa una alerta a la comunidad jurídica nacional para reformar los fundamentos legales, para que establezcan sanciones sin importar el transcurso del tiempo, pues, tan prologando es el tiempo del daño ocasionado a la mujer, como debe ser la obligación del Estado de castigar al agresor, lo cual solo es posible a través del reconocimiento de la Imprescriptibilidad de la acción penal de los delitos de violencia sexual, por atentar contra la Dignidad Humana de la Mujer.

\section{DIGNIDAD HUMANA}

Los orígenes del concepto de dignidad humana son, desde luego, filosóficos, antes que jurídicos, como bien ha resaltado Peces-Bar$\mathrm{ba}^{2}, \mathrm{y} \tan$ antiguos que se confunden con los inicios de nuestra civilización. Así, ya en el Génesis se encuentran los rasgos propios de la idea de dignidad, si bien una dignidad de raíz heterónoma, en cuanto que el hombre la recibe de Dios, quien lo hizo a su imagen y semejanza.

Esta es la concepción de la teología cristiana de la época medieval, en la que se concede al hombre una particularidad principal, si bien emanada de su condición infinita por su origen divino, llegando, incluso, a prolongarse en algunos aspectos hasta nuestros días.

Los griegos, elaboraron su propio concepto de dignidad, mezclando elementos autónomos y heterónomos, como se aprecia en los textos de Sófocles o en los de Platón. La cultura romana, por el contrario, alentará una visión del término social y política, ligada con la (Majestad).

De este modo, la noción romana de dignidad se refiere a la nobleza, a la función que se desempeñaba o a los méritos alcanzados a fa-

\footnotetext{
${ }^{2}$ Citamos textualmente: «en su origen dignidad humana no es un concepto jurídico como pueda serlo el derecho subjetivo, el deber jurídico o el delito, ni tampoco político como Democracia o parlamento, sino más bien una construcción de la filosofía para expresar el valor intrínseco de la persona derivado de una serie de rasgos de identificación que la hacen irrepetible, que es el centro del mundo y que está centrada en el mundo» (PECES-BARBA, G. La dignidad de la persona desde la Filosofía del Derecho, cit., pág 65)
} 
vor de los asuntos públicos. Se trataba, por tanto, de un reconocimiento que otorgaba la comunidad en atención a los méritos de los individuos y que permitía, en consecuencia, establecer diferencias entre unas personas y otras por sus comportamientos.

La concepción de la dignidad como algo autónomo, propio del hombre en sí mismo, se desarrolló, en el Renacimiento, gracias a la obra de autores como Buonnacorso de Montemagno, Gianozzo Mannetti, Pico Della Mirándola, Angelo Poliziano, Giordano Bruno, Francisco Recio, Juan Luis Vives o Fernán Pérez de la Oliva. Pero, es en el siglo XVIII a través de los escritos de Thomasius o Wolff y, de Kant quien introducirá elementos nuevos en el concepto de dignidad humana, que sin lugar a dudas, representan la máxima guía; cuando dijo: «lo digno es aquello que no tiene precio, que nadie puede ser tratado como un medio, o que la humanidad es en sí misma una dignidad ${ }^{3}$.

Indistintamente de la corriente de pensamiento o el enfoque (filosófico, teológico, sociológico, antropológico o jurídico) con el cual se pretenda explicar el concepto de Dignidad humana, todos convergen en un elemento común: La dignidad es un valor intrínseco del ser humano asociado a su capacidad innata de pensar, sentir y decidir (pensamiento, emociones y voluntad).

Por esta razón, la narrativa de cada enfoque es muy particular al adentrarse en la revisión profunda de cada uno. Donde cada enfoque ha dado su aporte para a la creación de los Derechos Humanos, cristalizados en instituciones jurídicas a finales del siglo XVIII y propiciadores de cambios profundos en los sistemas jurídicos y en las estructuras estatales e internacionales.

La declaración solemne de los derechos naturales de la persona, en el contexto de la Revolución Francesa y de la Revolución Americana, nutrió el constitucionalismo y contribuyó a la formación del Estado constitucional de Derecho.

Los Derechos Humanos tienen un fin instruccional, revelan en esencia la dignidad de la persona, y su valor único, pero también sus derechos y autonomía. Se refiere a una visión completa de la dignidad humana, y de la forma como debe ser atendido, aceptado y respetado el ser humano en todas sus áreas: física, emocional y espiritual. Bio-psico-social-sexual-espiritual.

${ }^{3}$ Cfr: KANT, L. Fundamentación para una metafísica de las costumbres, Madrid: Alianza Editorial, 2002, págs. 115, 116, 123 y 124. 
Este análisis interpretativo pretende mostrar en qué contexto está y hacia dónde va -en la historia el reconocimiento absoluto de la dignidad humana entre cada semejante. Porque el punto clímax más alto de la historia no es cuando se establece la Declaración Universal de los Derechos Humanos en su artículo 1: «Todos los seres humanos nacen libres e iguales en dignidad $y$ derechos $y$, dotados como están de razón y conciencia, deben comportarse fraternalmente los unos con los otros" sino cuando el ser humano llegue a la convicción de lo que significa la esencia de la dignidad humana, y por tanto amar, respetar, escuchar y no violentar a su semejante, cualquiera sea su género.

\section{VIOLENCIA SEXUAL}

La concepción de dignidad humana, constituye la gestación del principio de igualdad, inherente a todas las personas sin distinción de raza y sexo, que comporta el deber indeclinable de otorgarle a mujeres y hombres los mismos derechos, por lo que desde esta perspectiva es inconcebible la necesidad de generarse otros derechos o acciones positivas a favor de uno u otro género, sin embargo, esta realidad no aplica para el género femenino, como consecuencia de una histórica subvaloración.

Esta subvaloración, tiene su génesis en que la principal característica de nuestra cultura, es androcéntrica, centrada en el hombre, haciendo de éste el paradigma de lo humano, en la que el hombre, sus intereses y sus experiencias son el centro del universo, y los Estados a través de las legislaciones han contribuido a la hegemonía cultural que los hombres poseen en nuestra sociedad, toda vez que el orden que se impone antes la realidad social se hace desde las conductas y necesidades del hombre, haciéndose aceptada como normal y como parte del orden natural de las cosas, aún por aquellas personas que están subordinadas a ellos.

Estas perspectivas parciales, androcéntricas, que se imponen no han considerado ni los puntos de vista ni las experiencias de las mujeres, lo que ha resultado en la invisibilización de las violaciones cotidianas a sus derechos humanos, así como en la infravaloración de sus necesidades humanas. Por tanto, la noción de discriminación, generada en razón de las diversas modalidades de distinción, extinción o restricciones basadas en el sexo, lo cual produce un me- 
noscabo o anulación de sus derechos en cualquier campo de la vida social.

Así que, unas de las principales modalidades de discriminación contra la mujer tiene su génesis en el reduccionismo, al cual han sido sometidas al considerarlas en función de su sexualidad, lo que equivale a inferiorizarla, cosificarla o equipararla a un objeto con interés comercial.

En razón de ello la mujer suele ser sometida a contactos, insinuaciones o acciones de naturaleza sexual no consentidas, que comprende desde expresiones verbales con connotación sexual, "piropos», acciones invasivas con objetos sexuales o penetración por vía oral, anal y vaginal hasta confiscaciones de su cuerpo con fines comerciales, actos que pueden atentar contra la capacidad reproductiva de la mujer.

Son acciones que configuran distintas modalidades de Violencia Sexual, cuyo bien jurídico tutelado en el derecho internacional y nacional es la Libertad Sexual y Reproductiva.

No obstante, la problemática central generada por este tipo de delitos sufrido por la mujer no se limita a la violación de sus derechos o libertades, pues, la magnitud del daño trasciende la facultad que tiene la mujer de decidir responsable, voluntaria y libremente la forma de ejercer su sexualidad. Sin embargo, en los casos de este tipo de acciones antijurídicas, la magnitud del daño, suele delimitado solo en la vulneración de la libertad sexual, tal como solemos apreciarlo en las exposiciones de motivos de las legislaciones especializadas, en las sentencias y jurisprudencias.

Siendo necesario, ampliar el espectro del análisis, en razón que el impacto de la violencia ejercida contra la mujer, va más allá de la cuantificación de los daños físicos o psicológicos evidenciados de manera inmediata. Ante la situación planteada, es necesario reflexionar y visibilizar a plenitud la verdadera afectación causada a la mujer abusada sexualmente. También representados por los daños no físicos, lo cual transciende su humanidad y tiene serias repercusiones en su crecimiento personal, que se visibilizan con el transcurso del tiempo al incidir en la perdida de años de vida saludable, en razón del surgimiento de enfermedades asociadas al abuso sexual, en baja autoestima, sentimientos de venganza hacia el sexo opuesto, culpabilidad, entre otros. A lo que debe agregarse, las limitaciones en la posibilidad de desarrollar un proyecto de vida exitoso mediante la formación. Todo como consecuencia de la indefensión que genera un atentado directo a su valor e importancia como ser humano, que 
le impide alcanzar con su esfuerzo y autonomía moral, el máximo desarrollo posible de todas las dimensiones de su humanidad.

Se trata de una de las formas más extremas de ofensa y humillación que puede sufrir una persona como ser racional, con autonomía, sociabilidad e incluso espiritualidad, aspectos que al ser vulnerados atentan, claramente, contra la dignidad humana de la mujer.

La Dignidad Humana es una condición intrínseca de la persona, que no requiere reconocimiento del Estado, sino que le es inherente por el solo hecho de ser concebido. Por lo tanto, la concepción de dignidad humana es un concepto prepolítico y prejurídico. Vale decir, antecede a la condición de ciudadana/o y por tanto a los Derechos Humanos, por lo tanto al analizar el bien jurídico que se tutela en al sancionar las modalidades de violencia sexual, no debe ser centrado exclusivamente en los derechos humanos, pues, se trata también de un asunto de Dignidad.

Evidenciándose que el problema de la violencia en la actualidad es demasiado complejo como para dejarlo en manos de las autoridades encargadas de sancionar a los perpetradores: la sociedad es fundamental en la resolución de la problemática. No obstante, para que dé resultado la educación debe ser considerada no solo como un medio de instrucción, sino como un factor para inculcar valores y principios. En última instancia, un proceso de educación que forme buenos ciudadanos será el mejor instrumento para garantizar el respeto, amor y valoración de todas las personas sin distinción de género, como base fundamental en la construcción de un Estado Social.

\section{FUNDAMENTOS LEGALES}

Se fundamenta en un esquema legal y conceptual, los componentes son:

— La legislación y tratados internacionales.

Convención Interamericana para Prevenir, Sancionar y Erradicar la Violencia contra las Mujeres (Convención Belem De Pará) y la Convención para la Eliminación de Todas las Formas de Discriminación contra la Mujer (1979), conjuntamente con la Declaración de Naciones Unidas sobre la Eliminación de la Violencia contra la Mujer (1993). En la IV Conferencia Mundial sobre las Mujeres, celebrada en Pekín en 1995, 
- La legislación venezolana en materia de delitos sexuales contemplados: la Ley Orgánica sobre el derecho de las Mujeres a una vida libre de Violencia y la Ley Orgánica para la Protección del Niño, Niña y Adolescente.

— Informe Mundial sobre la Violencia y la Salud (2002), consecuencias físicas, psicológicas y emocional de las víctimas.

Así mismo, tiene como base La Dignidad Humana «esa capacidad que tiene el ser humano de pensar, sentir y decidir (pensamiento, emociones y voluntad) que Dios trasfirió al hombre y la mujer» y definida por la Declaración Universal de Derechos Humanos como inviolable, y debe de ser respetada y protegida.

\section{OPINIONES ESPECIALIZADAS. LA VIOLENCIA SEXUAL COMO UN ATENTADO CONTRA LA DIGNIDAD DE LA MUJER. PERSPECTIVA JURÍDICA, PSICOLÓGICA, TEOLÓGICA Y FILOSÓFICA}

Metodología de la investigación. Es de tipo documental con un diseño crítico-analítico y la técnica utilizada fue la interpretación jurídica se realizó una descripción del daño causado por la violencia sexual en la valoración de la mujer como ser humano. Desde el enfoque jurídico, psicológico y teológico; para este apartado se utilizó el criterio de tres (3) especialistas (opiniones especializadas,) y así situar un análisis e interpretación en común de las distintas visiones de un mismo tema: la violencia sexual como un atentado contra la dignidad de la mujer, con el propósito de promover la declaración de la violencia sexual como un delito imprescriptible y ayudar así a las partes intervinientes a actuar con mayor certeza jurídica. También se elaboró un análisis en la legislación internacional y nacional con respecto a la violencia sexual como un delito imprescriptible, y por último se propone una reforma de la ley orgánica sobre el derecho de las mujeres a una vida libre de violencia, perspectiva: la violencia sexual como un delito imprescriptible y un plan de atención integral a las mujeres víctimas de violencia sexual.

Esta focalización de las opiniones y argumentaciones especializadas en el tema de la violencia sexual como un atentado contra la dignidad de la mujer, desde el enfoque Jurídico, Psicológico, Teológico y Filosófico, establece los puentes necesarios para acercar a estas disciplinas, y así mostrar las consideraciones; porque cuando los problemas a tratar tienen que ver con el ser humano; el espectro de disciplinas se amplía. 


\title{
La violencia sexual como un atentado contra la dignidad de la mujer.-Perspectiva Jurídica
}

\author{
Opinión especializada:
}

Abga. Dhayana Carolina Fernández Matos, Especialista en Género y Derechos Humanos de las Mujeres.

La violencia sexual es una de las formas más grave de violación de derechos humanos que afecta derechos de distinta índole, entre ellos la integridad personal, la libertad personal e incluso, la vida, entendiendo que la obligaciones de los Estados en garantizar el derecho a la vida, no se cumple únicamente con no matar o no permitir la matanza, sino asegurar condiciones materiales para una vida digna y el desarrollo del proyecto personal de vida. Obviamente las consecuencias físicas, psicológicas y emocionales de la violencia sexual para las mujeres pueden afectar, incluso permanentemente, las posibilidades de desarrollar de un proyecto de vida y además, se trata de una de las formas más extremas de ofensa y de humillación que puede sufrir una persona y en ese sentido, es un claro atentado contra la dignidad humana.

A lo dicho, se puede agregar que hace ya un tiempo que Rhonda Copelon señaló que la violencia sexual se asemeja a la tortura y así ha sido reconocido en los tribunales penales internacionales (Caso Celibici).

Sin embargo, es necesario extender al ámbito interno la consideración de la violencia sexual como crimen de lesa humanidad y para ello, resulta oportuno el reconocimiento de los derechos sexuales, entre ellos, el derecho a tener el control sobre el propio cuerpo y el derecho a decidir libremente y sin coacciones sobre la sexualidad, como derechos humanos.

Así las cosas, la violencia sexual, asimilada a la tortura y por lo que implica este tipo de violencia para la mujer, constituye una violación grave de los derechos humanos y debería considerarse como un crimen de lesa humanidad, aunque no se trate de un ataque generalizado o sistemático contra una población civil, debido a la magnitud de las secuelas que este tipo de delito acarrea en la vida de las mujeres ya que atenta contra su dignidad personal y es un obstáculo al ejercicio de los derechos humanos.

La Corte Constitucional de Colombia en su sentencia T-881 del año 2002, ha definido tres elementos claves que deben estar presentes en la definición de dignidad humana, a saber: «(i) La dignidad humana entendida como autonomía o como posibilidad de diseñar un plan vital y de determinarse según sus características (vivir como quiera). 
(ii) La dignidad humana entendida como ciertas condiciones materiales concretas de existencia (vivir bien). Y (iii) la dignidad humana entendida como intangibilidad de los bienes no patrimoniales, integridad física e integridad moral (vivir sin humillaciones)».

De esta definición se puede concluir que el atentado contra la dignidad humana de las mujeres víctimas de violencia sexual queda evidenciado en el hecho de no poder vivir como quiera, porque la violencia sexual obstaculiza e incluso llega a impedir el desarrollo de un proyecto vital, también se truca el vivir bien, ya que las condiciones materiales pueden resultar insuficientes ante la magnitud del daño causado y, por último, resulta claro que las mujeres víctimas de este tipo de violencia, han padecido algunas de las formas más extremas de maltrato, ofensas y humillaciones que persona alguna pueda sufrir.

En el caso de Venezuela, el artículo 29 de la Constitución ha señalado que los crímenes de lesa humanidad y las violaciones graves de los derechos humanos son imprescriptibles.

La Sala Constitucional del Tribunal Supremo de Justicia de Venezuela, haciendo una interpretación de este artículo 29, estableció que los delitos de tráfico de drogas se asemejan a los crímenes de lesa humanidad por la magnitud del daño que estos delitos ocasionan en la población, declarando estos delitos como imprescriptibles.

Si esto es así, en el caso de violencia sexual aún con más razón existen suficientes elementos para considerar que se trata de una violación grave de los derechos humanos, que afecta la integridad de las mujeres y uno de los bienes más valiosos: la decisión sobre el propio cuerpo y cuyas secuelas pueden causar daños permanentes y de por vida, por lo que debería considerarse crimen de lesa humanidad y ser imprescriptible.

\section{La violencia sexual como un atentado contra la dignidad de la mujer. Perspectiva psicológica}

Las consecuencias físicas y psicológicas para la mujer víctima de violencia son múltiples a nivel de su salud integral, trastornos tales como dolor de espalda o de pelvis, trastornos ginecológicos, embarazos con complicaciones, enfermedades de transmisión sexual (ETS), dolores de cabeza, trastornos del sistema nervioso central y afecciones cardíacas o circulatorias son comunes, así como los «trastornos funcionales», como por ejemplo el síndrome de colón irritable, la fibromialgia, los trastornos del aparato digestivo y diversos síndromes 
de dolor crónico. La salud reproductiva de las mujeres también puede verse afectada por la violencia (Krug et al., 2002) ${ }^{4}$.

Las secuelas provocadas por el maltrato físico son evidentes, pero el impacto a nivel psicológico y el deterioro en la calidad de vida de estas mujeres es más difícil de identificar y evaluar. Para poder establecer el impacto de los efectos de la violencia contra la mujer sobre la salud individual y sobre la salud pública, se ha establecido un indicador basado en la pérdida de Años de Vida Saludables (AVISA). Este indicador permite calcular el número de años perdidos en relación a una esperanza de vida teórica, que determinaría el número de pérdida de AVISA que se producen como consecuencia de la violencia de pareja (Lorente, 2001). Sha considerado que los daños físicos suponen el $55 \%$ de los AVISA perdidos, mientras que los «no físicos», referidos a los psicológicos y a la salud reproductora, suponen el $45 \%$.

La OMS considera el maltrato como uno de los mayores asuntos de salud y de derechos humanos. En el Informe Mundial sobre Violencia y Salud de la OMS (Krug et al., 2002) se resumen sus principales consecuencias psicológicas:

- Depresión y ansiedad.

- Tristeza.

- Ansiedad o angustia.

- Fobias y trastorno de pánico.

- Insomnio.

- Cambios del estado de ánimo.

- Ganas de llorar sin motivo.

- Trastorno de estrés postraumático.

— Trastornos de la conducta alimentaria y del sueño.

- Trastornos psicosomáticos.

— Sentimientos de vergüenza y culpabilidad.

${ }^{4}$ KRUG, E.; DAHLBERG, L. L, MERCY J. A, ZWI, A. B, LOZANO, R., eds. (2002). Informe Mundial sobre la Violencia y la Salud. Ginebra: Organización Mundial de la Salud.

A inicios de los 80 se conceptualizó un indicador llamado Años de Vida Saludables (AVISA). En primera instancia, este indicador surge de un estudio realizado en Ghana en 1981. Ghana Equipo del Proyecto de Evaluación de Salud (Ghana Health Assessment Project Team 1981), que desarrolló un método para calcular cuantitativamente el impacto en la salud de diferentes procesos, con el fin de comparar el impacto potencial en la salud de la población de varios programas de intervención. La medición del estado de salud. Género, carga de morbilidad y establecimiento de prioridades en el sector salud. Hanson, Kara. 2000. Pág. 20.

3. LORENTE, M. (2001). Mi marido me pega lo normal. Barcelona: Crítica.

(C) UNED. Revista de Derecho UNED, núm. 17, 2015 


\section{- Conductas autolíticas y autodestructivas.}

- Abuso de alcohol y drogas.

- Irritabilidad.

- Baja autoestima.

- Suicidio o ideación suicida.

En la macroencuesta ${ }^{5}$ del Instituto de la Mujer de España se señalan los siguientes consecuencias psicológicas:

- Ganas de llorar sin motivos.

- Cambios de ánimo,.

- Ansiedad o angustia.

- Inapetencia sexual.

- Irritabilidad.

- Tristeza por pensar que no se vale nada.

- Dolores de cabeza.

- Gripe.

- Dolores de espalda o articulaciones.

- Insomnio o falta de sueño.

- Fatiga permanente.

${ }^{5}$ Macroencuesta de violencia de género 2011. Los informes del Instituto de la Mujer relativos a los resultados de las Macroencuestas de 1999, 2002 y 2006 se referían a maltrato contra las mujeres en el ámbito familiar y no distinguían la violencia de género de la violencia doméstica. En esos informes se distinguía el «maltrato técnico» (denominado de "Tipo A». que se deducía de una serie de respuestas de las encuestadas en las no se manifestaba expresamente el maltrato, pero de las que se deducía al mismo) y el «maltrato declarado» (denominado de «Tipo B», que se refería al que las mujeres manifestaban haber sufrido en el último año).

Las explotaciones de datos que se han realizado desde la Delegación del Gobierno se refieren exclusivamente a maltrato declarado y proveniente de varones que son o han sido marido o pareja de las mujeres encuestadas. En este sentido, en los cuadros de datos y gráficos, y en el correspondiente análisis, se tiene en cuenta:

El total de mujeres encuestadas

Las mujeres encuestadas que manifestaron no haber padecido NUNCA violencia de género

Las encuestadas que señalaron haber sufrido maltrato de género en el último año («Tipo B»)

Las encuestadas que dijeron que habían padecido maltrato de género alguna vez en la vida («Tipo C» que incluye, en todo caso, el maltrato de «Tipo B»).

Las encuestadas que declararon que sufrieron maltrato de género alguna vez en la vida pero que NO habían padecido ese maltrato en el último año («Tipo D» = «Tipo $\mathrm{C} »$ menos «Tipo B»). 
Otras respuestas habituales a consecuencia del trauma son las siguientes:

Minimización de lo ocurrido o negación del peligro

Distorsiones cognitivas (idealización de su agresor)

Disociación conductas de «cuidado» de su agresor como estrategia de afrontamiento (conductas de pena, apaciguamiento, justificación, complacerlo, decirle que busque ayuda terapéutica)

Corsi $\left(1995^{6}\right.$ dice que vivir en la violencia suscita una ansiedad extrema con respuestas de sobresalto y alerta constante puesto que la mujer siente que su integridad y a veces su vida, está amenazada. Agrega a los síntomas anteriores el déficit en la resolución de problemas: Alexitimia ${ }^{7}$, culpa por comisión u omisión, sentirse desbordada o agobiada, sensación de que ha cambiado su mundo, desilusión con respecto a la justicia y la autoridad, conductas autodestructivas, sentimientos de indefensión, problemas de memoria, problemas para relacionarse.

Como consecuencia de una agresión se producen cambios en el sistema de creencias.

Kilpatrick \& Otto $(1987)^{8}$ lo explican de la siguiente manera: la gente generalmente asume que su mundo es predecible, justo, legal y seguro, pero después de ser victimizado estos supuestos básicos son sacudidos, lo que produce un sentimiento de vulnerabilidad, rabia y una necesidad de comprender por qué fueron abusados. Cuando las personas han sido expuestas a hechos inesperados e incontrolables, reaccionan con pasividad (indefensión aprendida y desesperanza)

En la sexualidad humana se observan significativas diferencias en relación a la sexualidad puramente biológica. Es una dimensión fundamental de la identidad enraizada en el espíritu humano. Su cuerpo no es vehículo de su espíritu, sino que es la revelación de su unidad personal de espíritu y cuerpo. Su feminidad o su masculinidad impregnan su percepción del mundo y las relaciones que establece con él, a través de su libertad inteligente y sus decisiones.

${ }^{6}$ CORSI, J. (1994). Violencia familiar. Una mirada interdisciplinaria sobre un grave problema social. Buenos Aires. Paidó

${ }^{7}$ La alexitimia es un trastorno neurológico que consiste en la incapacidad del sujeto para identificar las emociones propias y, consecuentemente, la imposibilidad para darles expresión verbal.

${ }^{8}$ KILPATRICK, D. G., L. J. VERONEN y P. A. RESICK. 1987. «Las secuelas psicológicas a la violación: Evaluación y estrategias de tratamiento.» 
El sexo socio-cultural: por el que uno identifica a otros como hombres o como mujeres por su manera de vestir, comportarse, hablar entre otros. De acuerdo a las costumbres culturales aprendidas, como un medio para poder expresar la identidad y los comportamientos de hombres y mujeres, y el sexo psíquico: por el que uno se identifica con su propia sexualidad tanto en su fisiología como en las tendencias naturales que se derivan de ella. Estas son dimensiones que expresan la realidad humana que va más allá del elemento biológico. La identidad sexual se produce cuando uno descubre la relación adecuada que ha de existir entre la realidad objetiva de su cuerpo sexuado y la vivencia subjetiva de su sexualidad. Si uno es hombre, percibe su identidad como hombre. Si esta identificación no se da, hay una anomalía o desajuste en la personalidad.

El conjunto de factores educativos, familiares, sociales, y circunstancias personales que influyen en el desarrollo de un ser humano sexuado, influye en la configuración de su personalidad y de su individualidad, pero siempre como hombre o como mujer.

Siendo el ser humano un ser social, no sólo se identifica consigo mismo y con su sexo, sino que otros (con los que convive) le identifican por su sexualidad. Cuando uno se encuentra con otro ser humano, la primera constatación que hace, casi sin pensar, es acerca de la sexualidad del otro e intuitivamente adapta su manera de comportarse según sea hombre o mujer.

Por tanto, no se puede hacer de la sexualidad humana una actividad externa a la persona. Se expresa en todos sus actos y, por ello, no puede ser objeto de uso. Usar la sexualidad implicaría también usar al ser humano que se identifica con ella. Cualquier práctica que intenta usar al ser humano (como la prostitución, la pornografía, y la violencia sexual) niega el fin del ser humano y tiene consecuencias serias en su psicología, en su cuerpo y, sobre todo, en su espíritu.

\section{La violencia sexual como un atentado contra la dignidad de la mujer. Perspectiva teológica}

Dr. Samuel Marcano9. Especialista en Teología.

Desde la perspectiva teológica ni la violencia ni el maltrato a la mujer como manifestación específica de violencia son aceptados. La

\footnotetext{
${ }^{9}$ Samuel MARCANO. Maestría en Teología Bíblica. Contextualizada del seminario ProMETA con sede en Costa Rica. Blog: http://samuelmarcano.wordpress.com/ y Reflexiones Bíblicas Contemporáneas:
} 
violencia del ser humano contra su prójimo está claramente condenada en la Biblia ${ }^{10}$ (Éxodo 20:13).

La acción de Dios frente a la violencia se puede ver reflejado en el primer acto violento cometido en la historia de la humanidad. Este relato está contenido en Génesis 4:1-15. Es el relato del primer asesinato. Caín mata a su hermano Abel. Del texto llama la atención que tan pronto Caín se enoja contra su hermano, Dios hace todo lo posible por persuadirlo a cambiar de actitud:

Si hicieras lo bueno, podrías andar con la frente en alto. Pero si haces lo malo, el pecado te acecha, como una fiera lista para atraparte. No obstante, tú puedes dominarlo (Génesis 4:7).

Y después que Caín tomó su propia decisión en contra del consejo divino y mata a su hermano, entonces Dios interviene y castiga al culpable: -iQué has hecho! -exclamó el Señor-. Desde la tierra, la sangre de tu hermano reclama justicia.

Por eso, ahora quedarás bajo la maldición de la tierra, la cual ha abierto sus fauces para recibir la sangre de tu hermano, que tú has derramado. Cuando cultives la tierra, no te dará sus frutos, y en el mundo serás un fugitivo errante (Génesis 4:10-12).

Esa es la posición de Dios frente a la violencia: prevención y castigo (el castigo en caso que la persona haga caso omiso a la prevención). La Biblia enseña claramente que la esencia de Dios es el amor (1Juan 4:8). Por esa razón, él no apoya ningún tipo de acción violenta contra el ser humano porque eso va contra su propia naturaleza amorosa.

El castigo divino por la violencia cometida contra el ser humano toma la forma de una intervención directa de Dios contra el infractor o a través de las instituciones humanas establecidas con ese fin. Dios mismo fue quien instituyó la llamada Ley del Talión, que básicamente era una ley para poner límite a la violencia del hombre contra su prójimo (Génesis 9:6; Éxodo 21:23-25). De no establecerse tales limites, hubiese sido indetenible la violencia en el género humano.

Una razón subyacente por la cual Dios está en contra de la violencia del ser humano contra su prójimo, es porque el ser humano fue creado a imagen de Dios: Si uno derrama la sangre de un hombre, otro derramará la suya; porque Dios hizo al hombre a su imagen (Génesis 9:6) ${ }^{11}$.

${ }^{10}$ Biblia. Reina Valera Contemporánea (1960), revisión en castellano utilizada en América Latina desde hace más de cuatro siglos. Sociedades Bíblicas Unidas

${ }^{11}$ Estamos de acuerdo con los teólogos que señalan que la imagen de Dios en el hombre tiene que ver con esa capacidad que tiene el ser humano de pensar, sentir y

(C) UNED. Revista de Derecho UNED, núm. 17, 2015 
De acuerdo a la Biblia es esta imagen de Dios en el hombre la que realmente da dignidad al ser humano. Todos los seres humanos tienen la imagen de Dios por lo tanto todos tienen una dignidad intrínseca que no depende de su clase social, raza, sexo ni ninguna otra condición exógena a su naturaleza humana. Comprender esto es la base para el respeto mutuo entre las personas.

Hemos establecido que Dios rechaza y castiga la violencia del ser humano contra su prójimo. Pero cuando esta violencia es dirigida contra la mujer las implicaciones son mayores aun. Dios considera a la mujer como un vaso frágil (1Pedro 3:7).

Se puede apreciar con toda claridad la forma como Dios protegió a la mujer de maltratos físicos: Si algunos riñeren, e hirieren a mujer embarazada, y ésta abortare, pero sin haber muerte, serán penados conforme a lo que les impusiere el marido de la mujer y juzgaren los jueces. Más si hubiere muerte, entonces pagarás vida por vida (Éxodo 21:22-23).

Esta ley protegía a la mujer embarazada de ser golpeada accidentalmente en una discusión. Era probable que si dos hombres estaban discutiendo y la mujer de uno de los dos intervenía, pudiera ser golpeada. Dios actúa a favor de la mujer y de su bebé en caso de que ellos sufran algún tipo de violencia en medio de la discusión. Se nota aquí no solo una protección para la mujer sino para el fruto de su vientre (una legislación bastante adelantada para su tiempo).

También había una legislación en la ley de Dios para el caso de las violaciones sexuales: Pero si fue en despoblado donde el hombre encontró a la joven prometida, la forzó y se acostó con ella, morirá sólo el hombre que se acostó con ella; a la joven no le harás nada, no es rea de muerte; es como si uno ataca a otro y lo mata: él se la encontró en despoblado y la muchacha gritó, pero nadie podía defenderla (Deuteronomio 22:25-27).

Si se toma en cuenta que estas leyes fueron promulgadas para el pueblo de Israel aproximadamente en al año 1500 a. C. podremos entender mejor cuán importante era para Dios la protección de la mujer de la violencia física y sexual. Es bien sabido que las violaciones eran muy comunes y aceptadas en aquellas sociedades tribales. El hombre tenía «derecho» a poseer a cualquier mujer sin más restricción que su propio deseo sexual. Esta legislación exhibe un alto concepto de la dignidad de la mujer frente al acoso sexual penalizando al

decidir (pensamiento, emociones y voluntad) que Dios posee también y trasfirió al hombre y la mujer. 
infractor con la máxima pena (pena de muerte) por su violación. De hecho, se compara la violación aquí con el asesinato.

Desde la perspectiva teológica entonces, encontramos que Dios reprueba y castiga duramente la violencia física o sexual que se cometa contra la mujer porque ella trae consigo la imagen misma de Dios que le da dignidad como ser humano en el mismo nivel que el hombre. Cualquier violencia contra la mujer se considera, desde esta perspectiva, como una violencia contra la imagen de Dios. Por eso es duramente castigada en la Biblia.

\section{PROPUESTA PARA UNA REFORMA DE LA LEY ORGÁNICA SOBRE EL DERECHO DE LAS MUJERES A UNA VIDA LIBRE DE VIOLENCIA. PERSPECTIVA: LA VIOLENCIA SEXUAL COMO UN DELITO IMPRESCRIPTIBLE}

Se fundamenta en un esquema teórico-jurídico que sirve de guía en la reforma a la Ley orgánica sobre el derecho de las mujeres a una vida libre de violencia, en cuanto a la selección, diseño y organización de las acciones que conforman la propuesta.

Los componentes básicos de este esquema son:

1. Las teorías en que se basa:

- Medidas de afirmación positiva: las Acciones Positivas en el marco de las medidas dirigidas a eliminar las desigualdades existentes contra grupos históricamente discriminados, en este caso la mujer; sobre la base de los siguientes fundamentos: justicia compensatoria, justicia distributiva, utilidad social.

2. Jurisdicción venezolana:

- Constitución de la República bolivariana de Venezuela ${ }^{12}$.

- Ley Orgánica Sobre el Derecho de las Mujeres a una Vida Libre de Violencia. (Revisión de la prescripción de los delitos).

- Código penal.

${ }^{12}$ Constitución de la República Bolivariana de Venezuela. Artículo 218. Las leyes se derogan por otras leyes y se abrogan por referendo, salvo las excepciones establecidas en esta Constitución. Podrán ser reformadas total o parcialmente. La ley que sea objeto de reforma parcial se publicará en un solo texto que incorpore las modificaciones aprobadas. 
3. La metodología de intervención que promueve:

- Reforma a la Ley Orgánica Sobre el Derecho de las Mujeres a una Vida Libre de Violencia. Capítulo VI, de los delitos.

- Plan de atención integral a las víctimas de violencia sexual.

\section{REFORMA}

Ley Orgánica Sobre el Derecho de las Mujeres a una Vida Libre de Violencia. Capítulo VI de los delitos.

Se propone incluir un nuevo artículo que pasaría a ser el artículo 61, en la forma siguiente:

Imprescriptibilidad.

Artículo 61. No prescribe la acción penal de los delitos contra la libertad sexual de las mujeres y niñas, cuya competencia esté atribuida a los Tribunales Especializados en delitos de Violencia contra la Mujer.

Conforme al artículo 218 de la Constitución de la República Bolivariana de Venezuela, es competencia de la Asamblea Nacional, reformar total o parcialmente las leyes, por iniciativa del Poder Ejecutivo Nacional, la Comisión Delegada y a las Comisiones Permanentes, los y las integrantes de la Asamblea Nacional, en número no menor de tres, Tribunal Supremo de Justicia, cuando se trate de leyes relativas a la organización y procedimientos judiciales, Poder Ciudadano, cuando se trate de leyes relativas a los órganos que lo integran, Poder Electoral, cuando se trate de leyes relativas a la materia electoral, A los electores y electoras en un número no menor del cero coma uno por ciento de los inscritos e inscritas en el registro civil y electoral, Consejo Legislativo, cuando se trate de leyes relativas a los Estados.

En tal sentido, la propuesta se presentará ante la Comisión Nacional de Justicia de Género del Poder Judicial, a los fines que en ejercicio de la atribución que el artículo 204 ordinal 4 de la Constitución de la República Bolivariana de Venezuela le concede al Tribunal Supremo de Justicia proponga ante la Asamblea Nacional reforma parcial de la Ley Orgánica sobre el derecho de las Mujeres a una Vida Libre de Violencia. 
Plan de atención a las mujeres víctimas de violencia sexual.

Una mujer violentada física o psicológicamente carece de libertad para hablar o actuar. Golden y Frank, 1994

Physically or psychologically abused woman has no lacks freedom to speak or act. Golden y Frank, 1994

El Plan, nace desde el estudio de la presente tesis de grado «La Violencia Sexual como un atentado contra la Dignidad de la Mujer». Para la ejecución de este plan se utilizó como caso piloto en la 1era fase a los doscientos cincuenta y tres (253) casos atendidos por el circuito judicial de los tribunales de violencia contra la mujer. Puerto Ordaz Estado Bolívar, en el último trimestre del año 2014.

El Plan de Atención Integral ${ }^{13}$ está constituido por cinco (5) fases en las que se intervendrá con acciones específicas:

Fase 1. Intervención.

Fase 2. Salud.

Fase 3. Fortalecimiento y capacitación.

Fase 4. Recursos sociales.

Fase 5. Sensibilización y Prevención.

\section{CONCLUSIONES}

La Violencia Sexual, es reconocida en el ámbito internacional y nacional en sus diferentes formas y manifestaciones, en distintos contextos, entornos, circunstancias y relaciones, en todos los estratos sociales en el mundo. Aunado a ello las mujeres y niñas que afrontan múltiples formas de discriminación, son las más expuestas a un mayor riesgo de violencia, estableciéndose para ello condenas enérgicas a éstas formas de violencia contra las mujeres, con mayor énfasis a los abusos sexuales cometidos en contra de adolescentes y las niñas.

${ }^{13}$ A los fines de garantizar una efectiva atención integral a las mujeres víctimas de delitos sexuales es necesario tener en cuenta las necesidades de las víctimas, en este sentido, Ferrer, M. (2011, p. 324) señala acertadamente que «...las necesidades de las victimas pueden ser distintas y la sociedad tiene que tener muy en cuenta esto... no tendrá las mismas necesidades una mujer que ha sido violada por el esposo, que una mujer que ha sido violada por una autoridad...» a esto le agregaría, que no tiene la misma necesidad una mujer que ha sido violada a una mujer que ha sido acosada sexualmente. 
En ese mismo orden de ideas, de la lectura de los normativas legales, se evidencian la contundencia desde la comunidad internacional de promover y proteger todos los derechos humanos y libertades fundamentales, sean cuales fueren sus sistemas políticos, económicos y culturales, estableciéndose que todos los derechos humanos son universales, indivisibles e interdependientes y están relacionados entre sí, pero que previamente para llegar a esa declaración, fue necesario reconocer que los seres humanos tiene un valor que es intrínseco y supremo, por el solo hecho de nacer libres e iguales en Dignidad.

Los seres humanos tienen una dignidad intrínseca que no depende de su clase social, raza, sexo, ni ninguna otra condición exógena a su naturaleza humana, comprender esto, es la base para el respeto mutuo e incondicional entre las personas, no sometido a transacción.

Sin embargo, a los fines de el debido respeto a la dignidad humana en gran parte depende de la formación, cosmovisión de la o el juez o del operador del derecho, que comporta un trabajo progresivo a favor de su materialización, por tal motivo la superación de los diferentes retos a favor de los derechos de las mujeres exige la existencia un simple interprete.

Así, el concepto abstracto de dignidad humana no reviste ninguna utilidad para la defensa de los derechos humanos de las mujeres víctima, si el juez o jueza no se atreve a asumir un rol activo con miras a determinar su alcance en líneas prácticas.

Atreverse tiene que ser una actitud, necesaria en quienes tienen participación en las grandes luchas que aun requieren librar las mujeres y que pese al amplio recorrido que el mundo ha tenido para implementar mecanismos jurídicos que permitan castigarlos y erradicar esta modalidad de delitos, día a día continúan siendo víctimas de asaltos sexuales.

Por lo tanto, estas acciones que causan afectaciones físicas y emocionales que trascienden a la vulneración de los derechos humanos atentando contra su libertad, su voluntad y capacidad de decidir, lo que deja a las víctimas en una condición de indefensión y revictimización, lo que requiere una intervención inminente del Estado, dirigida a aplicar políticas judiciales, tendientes a lograr la sanción de las acciones, sin importar el transcurso del tiempo, pues, tan prologando es el tiempo del daño ocasionado a la mujer, como debe ser la obligación del Estado de castigar al agresor, lo cual solo es posible a través del reconocimiento de la Imprescriptibilidad de la acción penal de los delitos de violencia sexual, por atentar contra la Dignidad Humana de la Mujer. 